Z. klin. Chem. u. klin. Biochem.

8. Jg., S. 225-230, Mai 1970

\title{
Testosteron-Bestimmung in Plasma und Urin mittels "Competitive Protein Binding Method“
}

\author{
Von A. UetTwiLLer
}

\author{
Aus dem Laboratorium (Leiter: Dr. M. Keller) der Universitäts-Frawenklinik Basel (Direktor: Prof. Dr. O. Käser)
}

(Eingegangen am 28. Oktober 1969)

Es werden zwei Methoden zur Testosteronbestimmung im Plasma bzw. Urin beschrieben, die auf dem Prinzip der kompetitiven ProteinBindungsmethode betuhen. Bei der Plasma-Bestimmungsmethode wird das proteingebundene Testosteron vom freien Testosteron mittels Sephadex abgetrennt, während bei der Urin-Bestimmungsmethode diese Trennung mittels Florisil erreicht wird. Wir studierten die Plasmabindungskapazität für Testosteron in Abhängigkeit von der Plasma-Verdünnung und den Einfluß der Sephadex- bzw. Florisilmenge auf die Austauschreaktion. Die Zuverlässigkeitskriterien werden angegeben.

Die Untersuchungen von Plasma bei 15 Frauen (20-30jährig) ergaben Testosteron Werte von $20-100 \mathrm{ng}$ in $100 \mathrm{~m} /$.

Die Urin-Ausscheidungswerte von 20 Frauen (20-30jährig) lagen zwischen 2,0 und $28 \mu \mathrm{g} / 24$ Stdn.-Urin.

\section{Determination of testosterone in plasma and urine by the competitive protein binding metbod}

Methods are described for the determination of testosterone in plasma and urine, based on the principle of the competitive protein binding method. For plasma, the protein bound testosterone is separated from free testosterone with Sephadex, while Florisil is used for this separation with urine. The plasma binding capacity of testosterone was studied in relation to the plasma dilution; the influence of quantity of Sephadex or Florisil on the exchange reaction was studied. The criteria for reliability are reported.

Studies on the plasma of 15 women (20-30 years) gave testosterone values of $20-100 \mathrm{ng} / 100 \mathrm{ml}$.

The urinary excretion values for 20 women (20-30 years) lay between 2.0 and $28 \mu \mathrm{g} / 24 \mathrm{hr}$.

Die quantitative Bestimmung von Hormonmengen im Nanogrammbereich mit Hilfe der Doppel-isotopenverdünnungsmethoden ist bekanntlich sehr zeitaufwendig und relativ kompliziert.

Die Anwesenheit von Testosteron bindenden Proteinen von hoher Affinität und Bindungskapazität im Plasma gravider Frauen veranlaßte verschiedene Autoren (1-7) zur Ausarbeitung von kompetitiven Verdrängungsmethoden, welche relativ einfach und zeitsparend sind und nur kleine Aưsgangsvolumina biologischer Flüssigkeiten benötigen.

Die Interpretation von Testosteronausscheidungswerten im Urin kann durch verschiedene Faktoren wie Nieren-, Leber-, Herzfunktion und Wasserhaushalt erschwert werden. Es empfiehlt sich deshalb zusätzlich die Testosteronbestimmung im Plasma.

\section{Prinzip}

1. Inkubation: $\left.{ }^{3} \mathrm{H}-\mathrm{T}^{1}\right)+$ Protein $\rightleftharpoons{ }^{3} \mathrm{H}-\mathrm{T}-$ Protein $+{ }^{3} \mathrm{H}-\mathrm{T}+$ Protein

2. Austausch:

${ }^{3} \mathrm{H}-\mathrm{T}-$ Protein $+\mathrm{T}^{0} \rightleftharpoons \mathrm{T}^{0}$-Protein $+{ }^{3} \mathrm{H}-\mathrm{T}-\mathrm{T}^{\mathbf{0}}-$ Protein $+{ }^{3} \mathrm{H}-\mathrm{T}-$ Protein $+{ }^{3} \mathrm{H}-\mathrm{T}$

Diẹ Auftrennung der tritiierten Protein-Verbindungen (gebundenes Testosteron) vom $\left[{ }^{3} \mathrm{H}\right]$-Testosteron (freies tritiiertes Testosteron) wird allgemein nach fünf Verfahren durchgeführt: Dialyse, Sephadex, Florisil, Dextran-Aktivkohle und Ultrafiltration.

${ }^{1}{ }^{3} \mathrm{H}-\mathrm{T}^{\top}=$ tritiiertes Testosteron, $\mathrm{T}^{\mathbf{0}}=$ unmarkiertes Téstosteron.
In der vorliegenden Arbeit beschränkten wir uns auf die Trennung mit Hilfe von Sephadex (Plasmatestosteron) und Florisil (Urintestosteron). Diese beiden Trennmethoden erwiesen sich in unseren Händen als die technisch einfachsten und zeitsparendsten.

Das sich einstellende Verhältnis von $\left[{ }^{3} \mathrm{H}\right]-$ Testosteron zum Plasmaproteingebundenen $\left[{ }^{3} \mathrm{H}\right]$-Testosteron ist von großer praktischer Bedeutung. Wir untersuchten deshalb die Abhängigkeit dieses Verhältnisses von der Plasmaverdünnung und studierten die Trennleistung von Sephadex und Florisil.

\section{Sephadex/Puffer}

Wir bereiteten eine Sephadexsäule (1 g Sephadex G-25 fine) in $0,125 \mathrm{M}$ Phosphatpuffer $\mathrm{pH}=7,4$. Inkubationslösung $(1 \mathrm{~m} l)$ wird auf die Säule gebracht und mit der Pufferlösung eluiert. Die Trennung von $\left[{ }^{3} \mathrm{H}\right]$-TestosteronProtein vom $\left[{ }^{3} \mathrm{H}\right]$-Testosteron ist ersichtlich aus dem Erscheinen von $z$ wei scharf abgetrennten "peaks" (Fig. 1a). Gleichzeitig studierten wir durch Erstellung einer Konzentrationsreihe von 0 bis $5 \%$. Plasma-Puffer-Verdünnung (die $\left[{ }^{3} \mathrm{H}\right]$-Testosteron-Konzentration wurde dabei konstant gehalten) die Plasmabindungskapazität in \% für Testosteron in Abhängigkeit der Plasmaverdünnung. Das Resultat ist aus Abbildung $1 \mathrm{~b}$ ersichtlich. Die Abflachung der Kurve bei 5\% Plasmaverdünnung deutet auf eine Sättigung der Bindungskapazität hin. Die Austauschfähigkeit wird daher bei zu hohen Proteinkonzentrationen stark vermindert (Abb. 2).

Die Säule-Gel-Eluierung ist bei großer Bestimmungsanzahl aus verständlichen Gründen umständlich und 


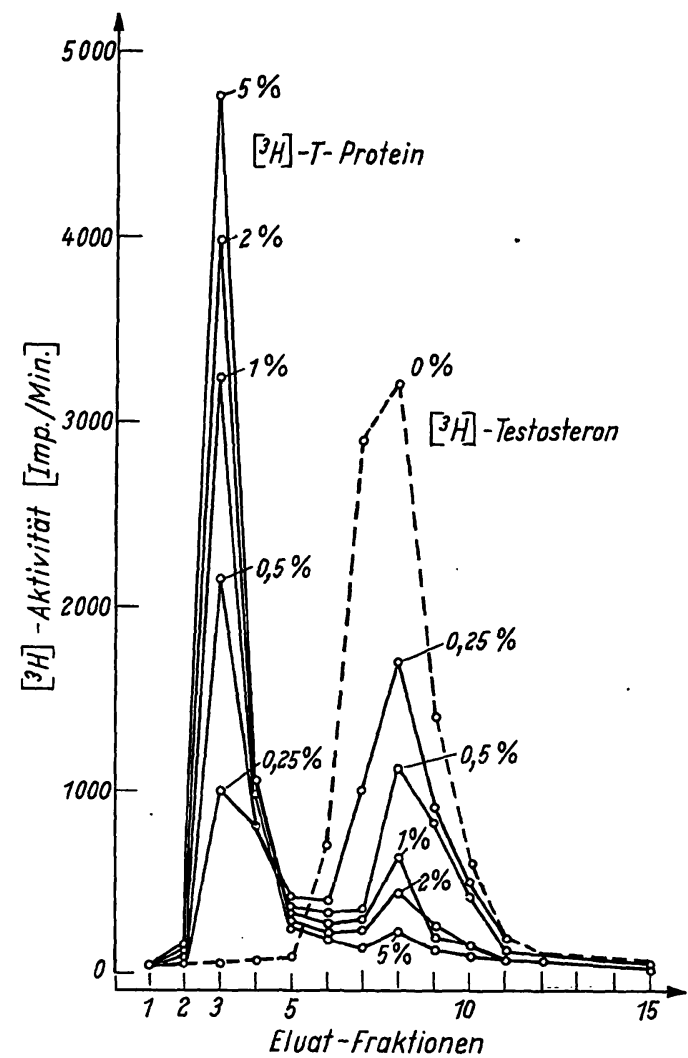

Abb. 1 a

Sephadex-Gel-Filtration einer Plasma-Verdünnungsreihe. Die Auftrennung von gebundenem und freiem $\left[{ }^{3} \mathrm{H}\right]-T$ estosteron in $1 \mathrm{ml}$ Inkubationslösung wurde durch eine Chromatographiesäule erreicht. Säule: $\varnothing 8 \mathrm{~mm}, 1 \mathrm{~g}$ Sephadex G-25 fine. Elutionsmittel: Phosphatpuffer $[\mathrm{pH}]=7,4(0,125 \mathrm{M})$

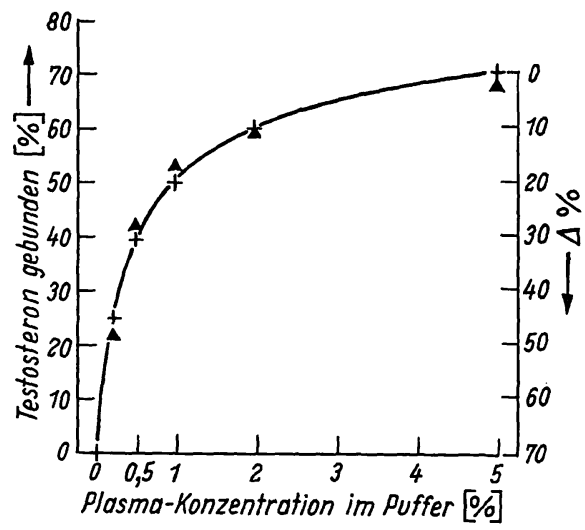

Abb. $1 \mathrm{~b}$

Abhängigkeit der prozentualen Bindung von der Plasma-Verdünnung. + - Säule-Gel-Filtration. A - Schüttelmethode

zeitaufwendig. $\mathrm{Zu}$ den gleichen Ergebnissen führt ein regelmäßiges Kippen oder Schütteln des InkubationsSephadex-Puffergemisches während einer bestimmten Zeit (Abb. 1b).

Die Inkubationslösungen werden zu den am Vorabend zubereiteten Sephadex/Puffer-Gläschen (200 mg Sepha$\mathrm{dex} / 1 \mathrm{~m} l$ Puffer) gegeben, geschüttelt, zentrifugiert und das überstehende tritiierte Proteingemisch abpipettiert und gemessen.

Wir untersuchten ebenfalls den Einfluß der Sephadexmenge auf die Austauschreaktion. Wir stellten bei zunehmender Sephadexmenge keine Abnahme der prozentualen Bindung von Hormon an Protein fest (Schüttelverfahren, Abb. 3).

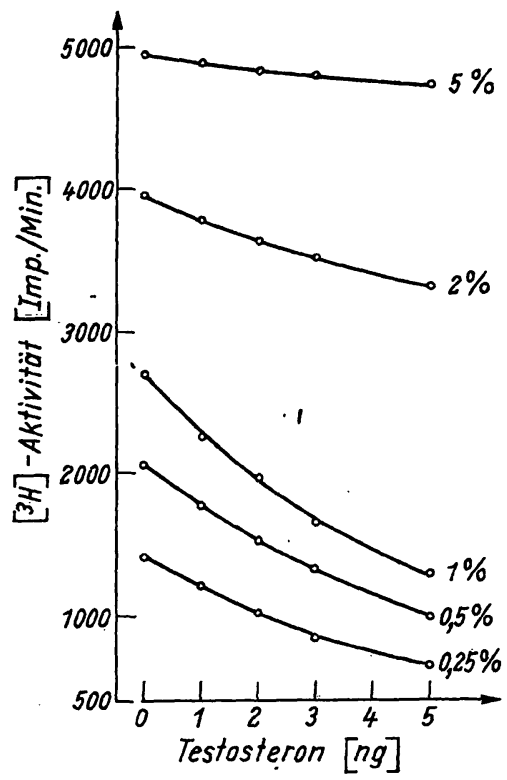

Abb. 2

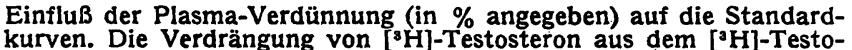
steron-Protein-Komplex nimmt mit erhöhter Verdünnung zu

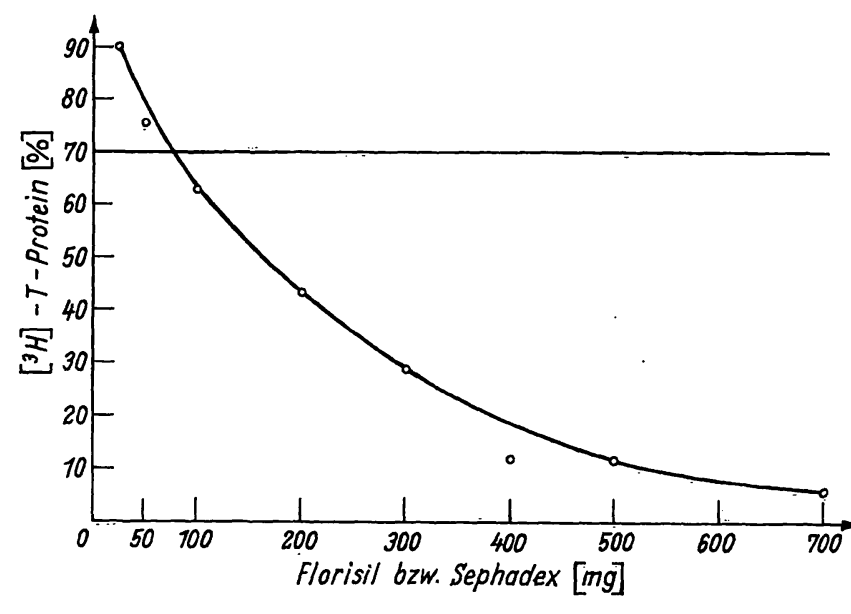

Abb. 3

Einfluß der Sephadex-Menge auf die Verdrängungsreaktion. In diesem

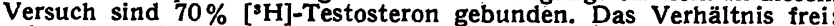
gebunden erfährt mit zunehmender Menge Sephadex keine Änderung (durchgezogene Linie).

Der Einfluß der Florisil-Menge ( $0-0)$ auf das Gleichgewicht ist deutlich erkennbar

\section{Florisil/Wasser}

Die Trennung der proteingebundenen von der freien Fraktion mit Hilfe von Florisil beruht grundsätzlich auf Adsorptionswirkung. Dieser Unterschied zur reinen Gel-Filtration mit Sephadex veranlaßte uns zur Untersuchung der Trennkapaziät von Florisil. Eine Säule wurde mit $1 \mathrm{~g}$ in Wasser ( $\mathrm{pH}=6,5)$ bereitet. Bei Abwesenheit von bindendem Protein konnte kein Testosteron in den wäßr. Eluatfraktionen gefunden werden. Wird eine Inkubationslösung (0,5proz. Plasma-WasserVerdünnung) auf die Säule gegeben, so läßt sich eine scharf abgegrenzte Fraktion erkennen, die sich eindeutig als die $\left[{ }^{3} \mathrm{H}\right]$-Testosteron-Protein-Fraktion erweist. Die $\left[{ }^{3} \mathrm{H}\right]$-Testosteron-Fraktion läßt sich danach mit Methanol eluieren (Fig. 4a). Zu analogen Ergebnissen mit den Sephadexversuchen führten Studien mit Florisil über die Plasmabindungskapazität in \% für Testosteron in 


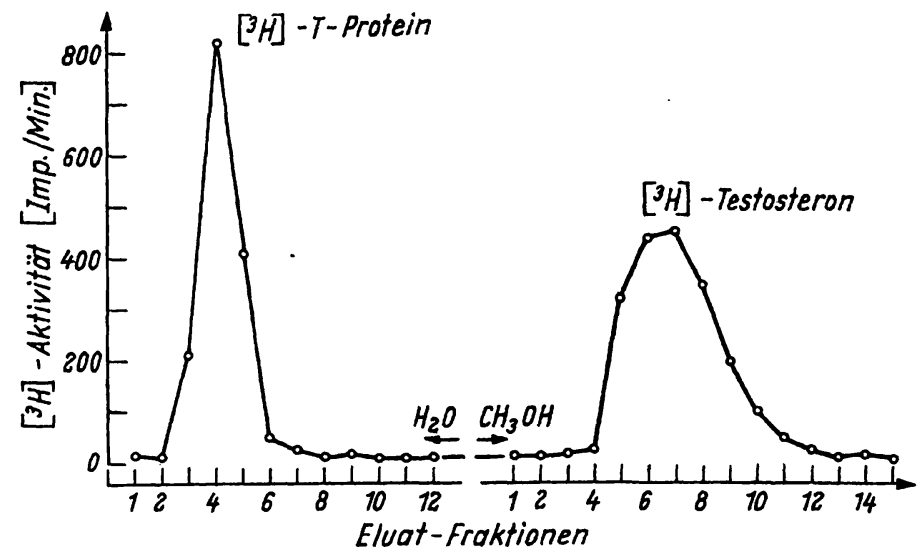

Abb. 4a

Trennung von $\left[{ }^{3} \mathrm{H}\right]-$ Testosteron von $\left[{ }^{2} \mathrm{H}\right]-$ Testosteron-Protein.

Säule: $\varnothing 8 \mathrm{~mm}, 1 \mathrm{~g}$ Florisil in $\mathrm{H}_{2} \mathrm{O} \mathrm{pH}=6,5,1 \mathrm{ml}$ Inkubationslösung. Die freie Testosteron-Fraktion wird mit Methanol eluiert

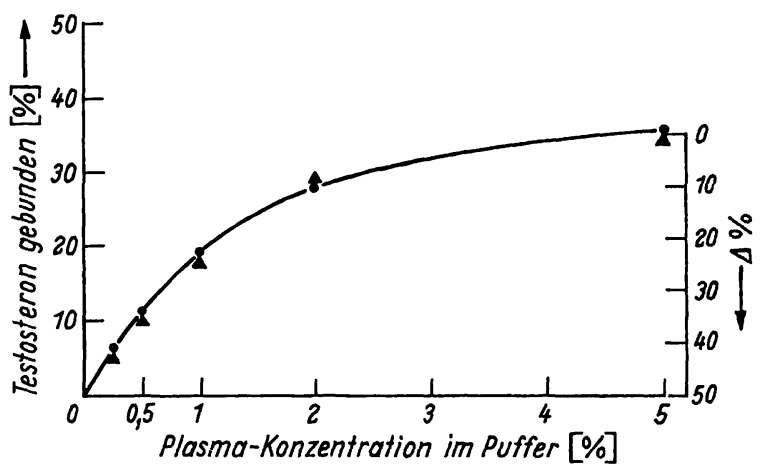

Abb. $4 b$

Abhängigkeit der prozentualen Bindung von der Plasma-Verdünnung. - - Florisilsäule. $\quad$ - Schüttelmethode

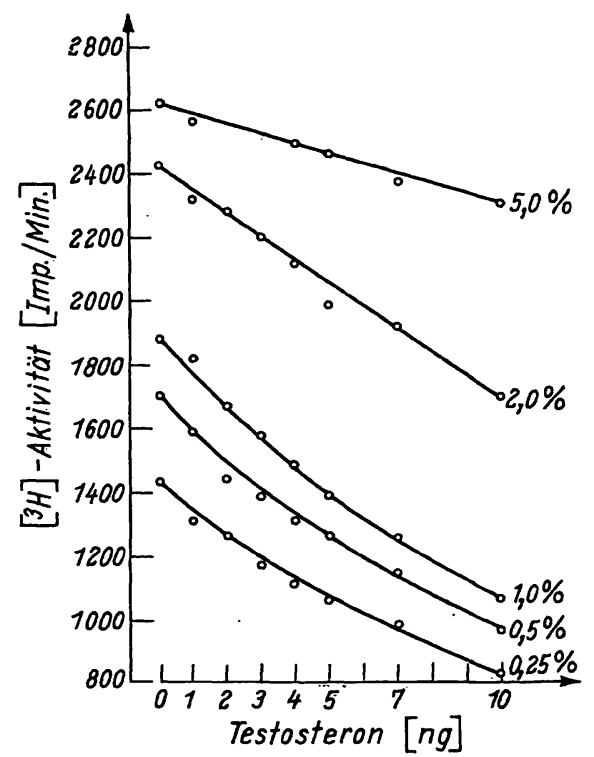

Abb. 5

Einfluß der Plasma-Verdünnung auf die Standardkurven (FlorisilMethode).

Deutlich erkennbar ist das geringere Austauschvermögen mit zunehmender Proteinkonzentration

Abhängigkeit der Plasmaverdünnung (Abb. 4b, PlasmaWasserverdünnungen von 0 bis $5 \%$ ). Auffallend ist der deutlich weniger steile Verlauf der prozentualen Bindungskurve (Abb. 4b). Diese Tatsache bewirkt eine geringere Empfindlichkeit der Austauschreaktion (Abb. 5).
Ein weiterer grundsätzlicher Unterschied gegenüber der Sephadexmethode besteht in einer feststellbaren Abhängigkeit der prozentualen Bindung von Hormon an Protein von der Florisilmenge (Abb. 3). Aus diesem Grunde erwies es sich als notwendig, kleine Mengen (40-80 mg) Florisil zu verwenden.

\section{Material}

Lösungsmittel

Ather, Methylenchlorid, Methanol, Åthanol, Dioxan, Åthylacetat, Benzol, Petroläther, Chloroform, Aceton spektralrein (Uvasol, Merck). Wasser: bidestilliert ( $\mathrm{pH}=6,5)$.

Phosphat-Puffer

$\mathrm{KH}_{2} \mathrm{PO}_{4}, \mathrm{Na}_{2} \mathrm{HPO}_{4} ; 0,125 \mathrm{M}, \mathrm{pH}=7,4$.

Sephadcx

G-25 fine (Pharmacia). $200 \mathrm{mg}$ in $1 \mathrm{ml}$ Phosphatpuffer/Bestimmung (über Nacht quellen lassen).

Florisil

60-100 mesh (Bender \& Hobein).

Testosteron-[1,2-3 $\mathrm{H}] \quad\left(\left[{ }^{3} \mathrm{H}\right]\right.$-Tetosteron) spezifische Aktivität $153 \mu \mathrm{C} / \mu \mathrm{g}$ (Amersham).

Dünnschichtchromatographische Reinigung.

Fließmittel: Chloroform/Aceton 80:20 ( $v / v)$.

[ $\left.{ }^{4} \mathrm{C}\right]-$ Testosteron

Spezifische Aktivität $191 \mu \mathrm{C} / \mathrm{mg}$. Verwendet für Wiedergewinnungsversuche.

\section{Testosteron}

Unmarkiertes Testosteron, dessen Reinheit mittels Dünnschichtchromatographie überprüft wurde.

Epitestosteron

Reinheit mittels Dünnschichtchromatographie überprüft.

Plasma

Schwangerenplasma (33.-36. Schwangerschaftswoche). Die Schwangeren wurden zuvor mit Primosiston (Schering AG, Berlin) behandelt. Das heparinisierte Blut wird sofort zentrifugiert und das Plasma in $1,2 \mathrm{ml}$ Portionen in sterilen Kunststoffröhrchen bei $-20^{\circ}$ eingefroren.

Plasmaverdünnung

Zur Urin-Testosteron-Bestimmung: $0,5 \%(\nabla / v)$ in bidest. Wasser $(\mathrm{pH}=6,5)$, enthaltend $0,067 \mathrm{ng}$ Testosteron- $\left[1,2-{ }^{3} \mathrm{H}\right] / \mathrm{ml}$.

Zur Plasma-Testosteron-Bestimmung: $1 \%(\mathrm{v} / \mathrm{v})$ in Phosphatpuffer $(\mathrm{pH}=7,4)$, enthaltend $0,134 \mathrm{ng}$ Testosteron- $\left[1,2{ }^{3} \mathrm{H}\right] / \mathrm{ml}$.

Radioaktive Messungen

Die Flüssigkeits-Scintillationsmessungen werden mit dem Mark I (Nuclear-Chicago) durchgeführt. Die wäßr. Proben werden zu $10 \mathrm{ml}$ Dioxanlösung, enthaltend $1 \mathrm{~g}$ Naphthalin und $50 \mathrm{mg}, 5-2$ Diphenyloxazol, gegeben. Meßzeit: $10 \mathrm{Min}$.

Glaswaren

Gereinigt mit Chromschwefelsäurc, Wasser, bidest. Wasser und Methanol.

Dünnschichtchromatographie

Kieselgel MN-GHR-UV 254 , Alox MN-G-UV ${ }_{254}$.

Die Adsorbens werden mit Methanol und Äther gewaschen und anschließend getrocknet.

Watte

Waschen mit verdünnter $\mathrm{HCl}(1 \mathrm{~N})$, Wasser, Methanol und Chloroform. 


\section{Methodik}

Plasma-Testosteron-Methode

Anfarbeitungsscbema

\section{Extraktion}

\begin{tabular}{|l|}
\hline $5 \mathrm{~m} l$ Plasma (Heparin) \\
$2 \times 20 \mathrm{ml}$ Äther \\
(je 30 Sek. schütteln) \\
$2 \mathrm{~m} l \mathrm{NaOH}(2 \mathrm{~N})$ \\
$\mathrm{Neutralwaschen} \mathrm{mit}$ \\
$\mathrm{H}_{2} \mathrm{O}$
\end{tabular}

Dïnnscbicbtchromatographie

Adsorbens: Kieselgel

Fließmittel:

Chloroform/Aceton $80: 20 \mathrm{v} / \mathrm{v}$

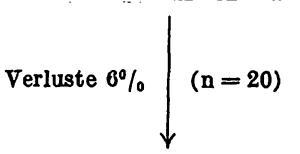

Sephadexmethode
Jede Analyse wird im Doppel ausgeführt. Die Ätherphase wird am Vakuumrotationsverdampfer $\left(30^{\circ}\right)$ eingeengt. Der getrocknete Rückstand wird in Petroläther $(5 \mathrm{~m} l)$ portionenweise gelöst und in ein Spitzzentrifugenglas überführt. Nach Eindampfen und Trocknen bei $40^{\circ}$ am Vakuum (Trockenschrank, Exsikkator) wird der Rückstand in $60 \mu \mathrm{l}$ Methanol gelöst und davon $2 \times 20 \mu l$ auf eine Dünnschichtplatte aufgetragen. (Die Dünnschichtplatte wird dabei auf einer elektrisch geheizten Kupferplatte auf $50^{\circ}$ erwärmt.) Zur Lokalisation im UV-Licht werden je $1 \mu \mathrm{g}$ Testosteron links und rechts der Analyse aufgetragen. Die lokalisierte Analysenzone wird sorgfältig ausgekratzt und mit $3 \mathrm{ml}$ Methanol bei $70^{\circ}$ eine Minute lang eluiert (der Eluierungsverlust beträgt $6-8 \%$ ).

\section{Meßtecbnik}

\section{a) Standardkurve}

Auf eine Einzelplatte werden im Doppel je 0,$5 ; 1 ; 2 ; 3$ ng Testosteron aufgetragen. Nach Entwicklung des Chromatogramms werden die entsprechenden Flächen ausgekratzt und mit Methanol eluiert (s. o.). Das Lösungsmittel wird abgedampft. Die getrockneten Rückstände werden mit je $5 \mathrm{~m} /$ Petroläther in die Inkubationsgläser überführt. Nach Abdampfen des Petroläthers und Trocknen am Vakuum werden je $1 \mathrm{ml} 1$ proz. Plasma-Pufferlösung zugegeben.

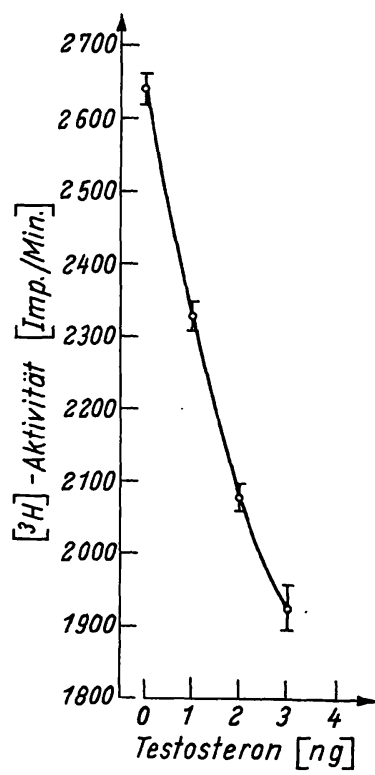

Abb. 6

Nach kurzem Schütteln wird $30 \mathrm{Min}$. bei Raumtemperatur inkubiert. $800 \mu l$ dieser Inkubationslösung werden dann zu den vorbereiteten Sephadex-Puffer-Röhrchen (200 mg Sephadex $/ 1 \mathrm{ml}$ Puffer) gegeben. Man mischt anschließend die gut verschlossenen Röhrchen 1 Min. lang mechanisch. Nach Zentrifugation (2 Min.) werden von der überstehenden Flüssigkeit $700 \mu l$ abpipettiert und zu $10 \mathrm{~m} l$ Scintillationslösung gegeben. Die Meßlösung wird vor der Messung eine Stunde lang bei $-4^{\circ}$ stehengelassen. Meßzeit: $10 \mathrm{Min}$. Die gemittelten Imp./Min. werden zur Erstellung der Standardkurve verwendet (Abb. 6).

b) Analysen .1

Die vereinigten Eluate der Analysenproben werden eingedampft, in $5 \mathrm{~m} l$ Petroläther wieder gelöst und in die Inkubationsgläser überführt. Die Weiterbearbeitung erfolgt genau gleich wie für die Standard-Vorschrift. Die zu bestimmenden ng Testosteronwerte können direkt auf der Standardkurve abgelesen werden. Man korrigiert die gefundenen Werte unter Berücksichtigung des Nullwerts und der Analysenverluste und rechnet auf $100 \mathrm{ml}$ Plasma um.

\section{Urin-Testosteron-Methode}

Aufarbeitungsschema:

Hydroly:se

\begin{tabular}{|l|}
$10 \mathrm{~m} l$ Urin \\
$1 \mathrm{~m} l \mathrm{H}_{2} \mathrm{SO}_{4}$ conc. \\
$10 \mathrm{Min}$. bei $90^{\circ}$
\end{tabular}

Diinnschichtchromatographie I

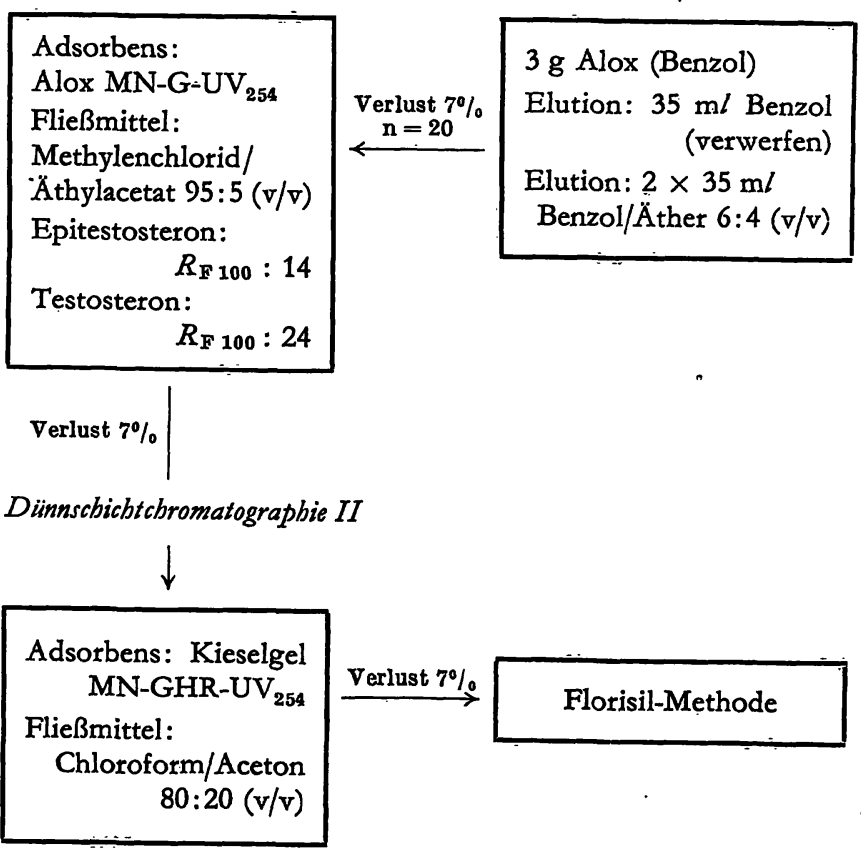

Jede Analyse wird im Doppel ausgeführt. Man extrahiert den hydrolysierten Urin durch Schütteln mit $2 \times 50 \mathrm{ml}$ Äther (je 30 Sek.). Nach Waschen der Ätherphase mit NaOH und Wasser wird der Äther abgedampft und der getrocknete Rückstand in Benzol gelöst und auf die Alox-Säule gegeben. Die Eluate (Benzol-Äther-Fraktion) werden am Vakuumrotationsverdampfer eingeengt und der Rückstand am Vakuum getrocknet. 


\section{Dünnschichtcbromatographie I}

Der Rückstand wird in $100 \mu l$ Methanol aufgenommen und davon $2 \times 20 \mu l$ auf die Dünnschichtplatte aufgetragen. Die Testosteron-Zonen werden ausgekratzt und mit Methanol wie oben beschrieben eluiert, das Lösungsmittel abgedampft und die vercinigten Rückstände am Vakuum getrocknet.

\section{Dïnnscbicbtchromatograpbie II}

Der Rückstand der I. Dünnschichtchromatographie wird in $60 \mu l$ Methanol aufgenommen und davon $10 \mu l$ auf die Platte aufgetragen. Eluierung, Abdampfung und Trocknung wie oben beschrieben.

\section{Meßtecbnik}

\section{a) Standardkurve}

Aus einer Testosteron-Stammlösung ( $10 \mathrm{mg} / \mathrm{ml}$ A thanol) werden entsprechende Volumina, die $1,2,3,4,5,6,7,8,9,10 \mathrm{ng}$ enthalten, in die Inkubationsgläser pipettiert. Nach sorgfältigem Abdampfen des Lösungsmittels am Vakuum werden je $2 \mathrm{ml} 0,5$ proz. Plasmalösung zugegeben und die Gläschen kurz geschüttelt. Die Inkubationszeit beträgt eine Stunde. Dann Zusatz von je $80 \mathrm{mg}$ Florisil in jedes Inkubationsgläschen. Nach mechanischem Mischen (1 Min.) wird $5 \mathrm{Min}$. stehengelassen. Je $900 \mu l$ der überstehenden Lösung werden zu $10 \mathrm{~m} l$ Scintillationslösung gegeben. Messung: Es gelten die gleichen Meßbedingungen, die bei der SephadexMethode beschrieben wurden. Aus den aufgetragenen Werten entsteht die Eichkurve (Abb. 7).

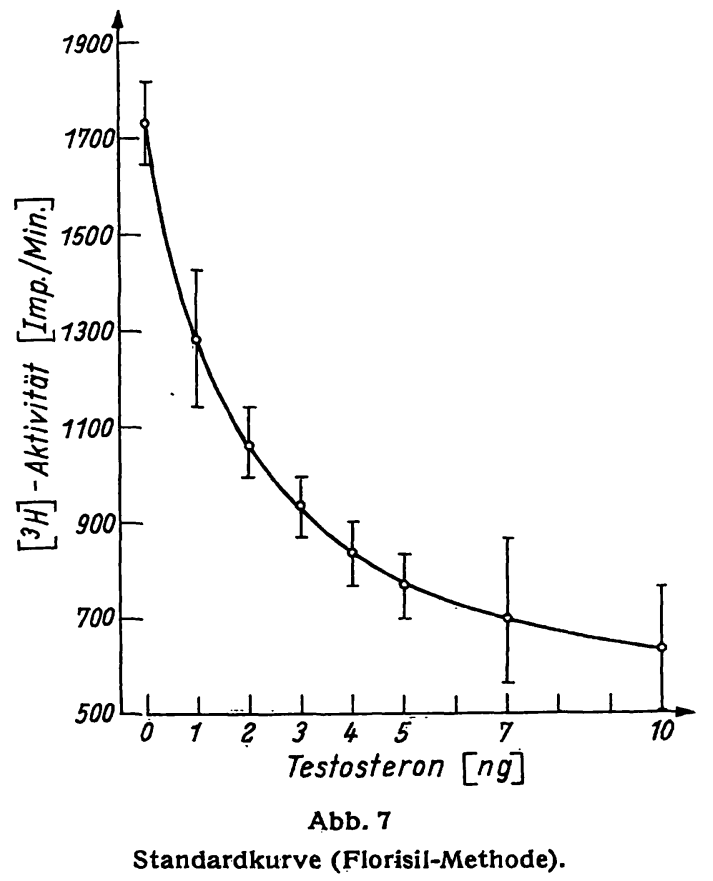

Plasma-Verdünnung 0,5\%. Mittelwertkurve aus 10 Standardkurven

\section{b) Analysen}

Die Eluate der Dünnschichtchromatographie II werden analog der Plasma-Testosteron-Methode behandelt. Die gefundenen Werte werden unter Berücksichtigung der Nullwerte und der Analysenverluste aưf die 24-Stdn.-Urinmenge umgerechnet.

\section{Zuverlässigkeitskriterien der Methoden}

Die Wiedergewinnungsversuche werden mit $\left[{ }^{14} \mathrm{C}\right]-$ Testosteron (25000 Imp./Min.) ausgeführt. Das markierte Testosteron wurde vorerst dünnschichtchromatographisch gereinigt.

\section{Ricbtigkeit der Methoden}

Plasma: $86 \%$

Urin: $\quad 79 \%$

Tab. 1

Verluste während des Analysengangs

\begin{tabular}{lcllll}
\hline \multicolumn{3}{c}{ Plasma } & \multicolumn{4}{c}{ Urin } \\
\hline & $\%$ Verluste & $\mathfrak{n}$ & & $\%$ Verluste & $\mathrm{n}$ \\
Extraktion & 8 & 20 & Hydrolyse, & & \\
Dünnschicht & 6 & 20 & Extraktion, Säule & 7 & 20 \\
& & & Dünnschicht I & 7 & 15 \\
& & & Dünnschicht II & 7 & 15 \\
\hline
\end{tabular}

Beträchtliche Schwierigkeiten bei diesen hochempfindlichen Methoden bereiten die unspezifischen Nullwerte. Die verschiedenen Ursachen wurden schon von Karo und Horton (7) beschrieben. Die möglichen Störungen durch Lösungsmittelrückstände schlossen wir durch die strikte Verwendung von spektralreinen Lösungsmitteln aus.

Beim Gebrauch von unbehandeltem Kieselgel bzw. Alox erhielten wir bei der Extraktion von $5 \mathrm{ml}$ dest. $\mathrm{H}_{2} \mathrm{O}$ Nullwerte von 1,8 bis 2,3 ng/Probe. Unter Verwendung von mit Methanol und Äther gewaschenen Adsorbens erhielten wir Werte von 1,0 bis 1,3 ng/Probe. Wirklich annehmbare Nullwerte von 0,2 bis $0,5 \mathrm{ng} /$ Probe erhielten wir erst, als auch die Standards unter genau denselben Bedingungen (Dünnschicht-Eluierung) behandelt wurden.

\section{Zusatzversuche}

Bei Zusatz von $3 \mathrm{ng}$ reinem Testosteron zu $5 \mathrm{ml}$ dest. $\mathrm{H}_{2} \mathrm{O}(\mathrm{n}=10)$ erhielten wir unter Berücksichtigung der Nullwert- und Verlust-Korrektur Werte von 2,7 bis 3,5 ng. Die Abweichung vom zugegebenen Wert beträgt 10-14\%. Diese prozentualen Abweichungen sind mit dem gefundenen Variationskoeffizienten der $\mathrm{Me}-$ thode vergleichbar.

\section{Präzision der Methoden}

Pool-Plasma: $\mathrm{n}=25 ; \overline{\mathrm{X}}=67,5 \pm 8,2 \mathrm{ng} ; \mathrm{VK}=12 \%$ Urin: $\quad \mathrm{n}=12 ; \overline{\mathrm{X}}=5,3 \pm 0,45 \mu \mathrm{g} ; \mathrm{VK}=8,5 \%$

\section{Empfindlicbkeit der Methoden}

Plasma : Unter den beschriebenen Meßbedingungen können noch $11,3 \mathrm{ng}$ Testosteron in $100 \mathrm{~m} l$ Plasma bestimmt werden.

Urin: Die noch bestimmbare Urin-Testosteron Menge beträgt $4,2 \mu \mathrm{g}$ in $1000 \mathrm{~m} l$ Urin.

Die Empfindlichkeit konnte unter Verwendung von Albuminfreiem Plasma (Fraktionierung mit Rivanol) bei den von uns verwendeten Plasma-Verdünnungen nur unwesentlich gesteigert werden.

\section{Spezifität der Methoden}

Die Spezifität der Methoden ist ausgezeichnet. Versuche ergaben, daß eine zusätzliche Papierchromatographie zur weiteren Reinigung der Plasmaextrakte 
überflüssig ist. Die Urinextrakte hingegen mußten einer viel intensiveren Vorreinigung unterworfen werden. Es wurde deshalb zusätzlich eine Säulenchromatographie angewendet. Die Möglichkeit einer Verdrängung von $\left[{ }^{3} \mathrm{H}\right]$-Testosteron aus dem Protein-Komplex durch andere anwesende Steroide wurde am Beispiel des Epitestosterons studiert. Mit Epitestosteronmengen $z$ wischen 0,5 und 10 ng stellten wir keine Verdrängungseffekte fest, welche die unspezifischen Nullwerte überstiegen.

\section{Zeitaufwand der Methoden}

Plasma-Testosteron: 5 Doppelbestimmungen täglich. Urin-Testosteron: 4•Doppelbestimmungen täglich.

\section{Literatur}

1. Slaunwhite, W. R. und A. A. Sandberg, J. Clin. Invest. 38 , 384 (1959). - 2. Pearlman, W. H., O. Crépy und M. Murphy, J. Clin. Endocr., Springfield 27, 1012 (1967). - 3. Pearlman, W. H. und O. CRÉPY, J. biol. Chemistry 242, 182 (1967). 4. Vermeulen, A. und L. Verdonck, Stetoids 11, 609 (1968).
5. Maguelone, G. F., M. A. Rivarola und C. J. Mrgeon, Steroids 12, 323 (1968). - 6. HALLBerg, M. C., E. M. ZorN und R. G. Wreland, Steroids 12, 241 (1968). - 7. Kato, T. und R. Horton, Steroids 12, 634 (1968).
Dr. A. Uettwiller Schanzenstr. 46 $\mathrm{CH} 4056$ Basel 